Article

\title{
Analysis of the Thermal Environment in Pedestrian Space Using 3D Thermal Imaging
}

\author{
Xuexiu Zhao ${ }^{1}$, Yanwen Luo ${ }^{2}$ and Jiang $\mathrm{He}^{1,3, *}$ \\ 1 Department of Architecture and Urban Planning, College of Civil Engineering and Architecture, \\ Guangxi University, Nanning 530004, China; zxx950204@163.com \\ 2 Academy of Architecture and Arts, Guangxi Arts University, Nanning 530007, China; \\ wangyiyigevip@163.com \\ 3 Guangxi Key Laboratory of Disaster Prevention and Engineering Safety, Nanning 530004, China \\ * Correspondence: kakohejiang@gxu.edu.cn; Tel.: +86-0771-3232057
}

Received: 23 June 2020; Accepted: 13 July 2020; Published: 16 July 2020

check for updates

\begin{abstract}
Pedestrian space is an important place for people's outdoor activities. Its thermal environment affects pedestrian walking experience, route selection and physical health. This study presents a 3D thermography-based method to analyze and evaluate the spatial distribution of thermal comfort. The proposed 3D thermal image was generated using 3D city models captured by an unmanned aerial vehicle (UAV) and thermal images gathered by an infrared camera. It can visualize construction elements, but also simply output surface temperatures at selected points. This paper described the process of using 3D thermal images to analyze the built environment, and selected two pedestrian spaces as case study objects. Their thermal images and mean radiant temperatures (MRT) were obtained from field measurement data collected by a drone and infrared camera. The following findings were obtained: (a) the MRT difference in the pedestrian space between sunlit and shaded areas was more than $3{ }^{\circ} \mathrm{C}$; (b) the MRT values at the measurement points near vegetation were lower; (c) when the ratio of street height to width $(\mathrm{H} / \mathrm{W})$ was larger, the MRT values at all measurement points varied slightly. These findings can be used for the designers to evaluate and improve the thermal environment in pedestrian space.
\end{abstract}

Keywords: 3D thermal image; pedestrian space; mean radiant temperature; spatial distribution; outdoor thermal comfort

\section{Introduction}

Outdoor public space is an important living environment where people often fulfill leisure and entertainment activities. Well-designed and thermally comfortable space can attract more people to stay [1]. Eliasson's research [2] in Gothenburg showed that the cleanliness index, temperature and wind speed have a great impact on the number of people in outdoor public space, accounting for more than $50 \%$. In particularly, creating a comfortable thermal environment can control urban thermal stress, and then effectively reduce the incidence of heat-related disease [3]. In the study of Shooshtarian and Kumar $[4,5]$, it was found that if thermal comfort in the outdoor space is within the acceptable range, the occupant would spend more time outdoors. Therefore, thermal comfort is one of the important factors for the effective use of outdoor public space.

On the other hand, with rapidly increasing of urban population and expanding of built-up areas, pedestrian space plays an important role in human daily lives [6], since it is a major place for outdoor activities as well as a symbol of urban planning [7]. Comfortable and pleasant streets can provide pedestrians a good experience and feeling, attract more tourists, increase income of the urban tourism industry and also reduce the risk of urban heat islands (UHI) and heat waves to human 
health, especially outdoor workers $[7,8]$. Thus, the research on thermal comfort in pedestrian space has a positive impact on improving the microclimate environment and promoting sustainable urban development [9].

As described in current studies [10-13], the factors that affect thermal comfort in pedestrian spaces include both natural factors (such as geography, climate and season) and artificial factors (such as street aspect ratio, vegetation and paving materials). Xuan Ma $[6,7]$ used the physiologically equivalent temperature (PET) to determine the thermal comfort range, and extended the optimal walking time in pedestrian space by increasing building height and vegetation coverage. In addition, there are different thermal comfort ranges for different climates, space design and pedestrian genders [14,15]. As found in reference [1], some research has shown that the universal thermal climate index (UTCI) in cold regions was wider, males felt more comfortable than females and the elderly were more adaptable to extreme weather conditions. For the walking dimension space, optimizing the shape of streets and increasing vertical greening can enhance the pedestrian's physiological feeling, which is to create a comfortable sensation in the pedestrian space from another perspective $[8,16,17]$. These studies analyzed thermal comfort in terms of evaluation indicators such as predicated mean vote (PMV), PET, UTCI, wind speed and others by means of field measurements and numerical simulation. However, the previous studies demonstrated that half of thermal comfort is driven by radiant heat exchange between the occupant and environment [18], and thermal radiation is one of the important factors that affect thermal comfort in the built environment, especially in the outdoor space [19]. Therefore, it is important to evaluate and analyze outdoor thermal comfort in terms of the mean radiant temperature (MRT). On the other hand, the MRT has an obvious spatial distribution, which is particularly important for outdoor environment analysis [20-23]. At present, the field measurement data of MRT is relatively singular and its simulation results are presented in two-dimensional (2D) images [23-25]. There is still a lack of effective means to visualize the MRT spatial distribution in the analyzed environment. In order to fill this gap, this study presents a method to obtain three-dimensional (3D) thermal images by combining 3D models from aerial photography of unmanned aerial vehicles (UAV) with 2D thermal images simultaneously captured by an infrared camera. There are a number of 3D thermograph-related research cases on heat loss of building envelopes [26], pollutant diffusion detection [27] and crime scene investigation [28]; however, their equipment is integrated as a unit under consideration of the research characteristics in the related fields, although its cost is very high, and the analyzed area is small. Due to these reasons, it is not suitable for outdoor thermal environment research. In summary, the method proposed in this paper is easy to operate and suitable for researchers in different fields, and its data are relatively accurate and fast to collect [28-30]. Furthermore its cost is lower than the UAV equipped with infrared cameras [31-33]. The 3D thermal images generated can provide visualization of the building layout, surrounding environments and other construction elements, but also simply output surface temperatures at selected points. Particularly, it can be used to estimate the MRT at different locations in the study area and analyze the spatial distribution of thermal comfort.

This paper describes how to prepare 3D thermal images and estimate MRT distribution in the observed space. As case study, two pedestrian spaces with different surrounding conditions objects were selected and field measurement results were analyzed. Based on the results of the analysis, effective strategies for creating a comfortable and pleasant pedestrian space are also discussed.

\section{Methodology}

Owing to the advantages of low cost, high resolution and high efficiency, UAVs are widely used in the fields of industry, agriculture, forestry and construction [34-37]. In the field of urban planning and city management, this technology is often used to obtain 3D models for satisfying research demand from governments and designers [8]. On the other hand, in order to study the causes and influencing factors of UHI formation in the urban built environment, infrared thermal cameras are often used to capture surface temperature distributions, and their thermal images are basic data for analysis and evaluation [38]. This measurement approach is intuitive in its data and wide in application [29]. 
Therefore, this study employed the above-mentioned remote sensing technology to obtain 3D thermal images. The specific steps are described as follows.

\subsection{Acquisition of 3D Models}

Before UAV photography, the following preparatory work is necessary. The first step is an on-the-spot investigation in the observed area, determining the observation range and flight height, according to the observed building height, ground resolution etc. The second step is to assemble a UAV and prepare the flight plan on a sunny day, including camera exposure parameters and route parameters [39]. The third step is to conduct oblique photogrammetry at a fixed-point, based on the predetermined route. Meanwhile, the observation process is also fed back to the ground monitoring system, which is beneficial to make up the missing parts. After the aerial photography is completed, the UAV automatically returns to the takeoff point. The data collected are prepared for image preprocessing, including checking the orthophoto and oblique images of measuring points, and light modification. Next, the aerial triangulation encryption is made on Context Capture software (the version of 4.4, the company of South Surveying, Guangzhou, China) for improving the quality of the model $[40,41]$. Finally, the 3D model of the observed area is obtained.

\subsection{Acquisition of $2 D$ Thermal Images}

In order to ensure the uniformity and data accuracy between thermal images and 3D models, thermography in the study area was simultaneously taken using an infrared camera by the operator on the ground during UAV flight. A nesting method is used for thermography. The thermography work needed to be completed within one hour for reducing the effect of measurement time and weather changes on the surface temperature [38]. The shooting angle must be parallel and there needs to be at least $30 \%$ image overlap between adjacent shooting points [33,41]. It is important to avoid low angle shoot and high angle shoot. After thermal images for all enclosing surfaces were captured, images were checked for blurring and low coincident rate for ensure the accuracy and completeness of the image data. Finally, the captured thermal images were output in a uniform temperature range.

\subsection{D Thermagraphy Processing}

3D thermography was prepared as follows, using the 3D model and precise 2D thermal images described. The first step was to split joint the thermal images using Adobe Photoshop software (CS5, the company of Adobe, San Jose, CA, US.). Secondly, the 3D model was imported into 3Dmax for removing non-measured environments, inspecting the building façades and other model processing. Then the arranged thermal images for the façade surfaces were attached to the 3D model by the surface-aligned method [34,42]. Lastly, the edge thermal images were supplemented and adjusted. Through this process, the thermal images for all of enclosed façades in the observation area were stitched with the model and the 3D thermal images obtained, as shown in Figure 1. 


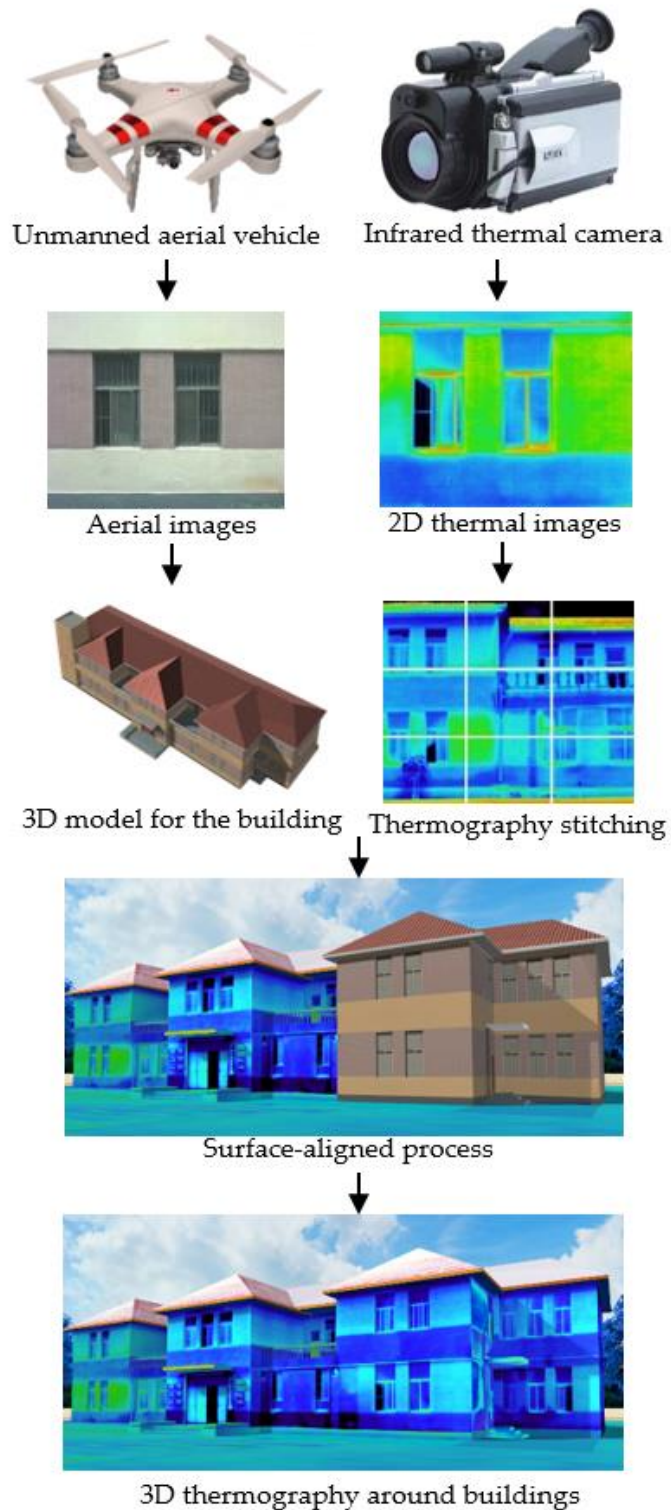

Figure 1. Processing flow of 3D thermography preparation.

\subsection{Estimation of Mean Radiant Temperature}

Solar radiation has a great impact on the outdoor thermal environment, resulting in different temperatures on different surfaces in the urban environment [19,43]. Moreover, thermal radiation occurs between objects, and it is also one of the main forms in heat transfer. Thus, the MRT is commonly used to evaluate the thermal radiation environment in current research [44,45]. The MRT at a point is defined as the uniform temperature of an imaginary enclosure in which radiant heat transfer from the human body or object equals the radiant heat transfer in the actual nonuniform enclosure, as shown in Figure 2. The larger the surface and the closer one is to it, the more thermal effect the surface has on the human [46,47]. The MRT at a point in pedestrian space is determined from temperatures of the surfaces that enclose the point, and can be approximately estimated by Equation (1) [48]. In this equation, $n$ is number of all enclosing surfaces; $F_{i}$ and $F_{s k y}$ are the view factors from the target point to surface $i$ and the sky, respectively; $T_{S i}$ and $T_{s k y}$ are the temperatures of surface $i$ and the sky, respectively; $\varepsilon_{i}$ and $\varepsilon_{0}$ are the emissivity of surface $i$ and the human body, respectively. Their standard values are approximately 0.9 and 0.97 , respectively [49], so $\varepsilon_{i}$ and $\varepsilon_{0}$ can be considered as 1 . Applying $\varepsilon_{i}=1$ and $\varepsilon_{0}=1$ to Equation (1), Equation (2) can be obtained. At the same time, the view factor is defined as the percentage of radiant energy emitted from one surface to another surface, which reflects the 
geometric shape and positional relationship between different objects. In this study, pedestrians were regarded as micropoints, and the view factor evaluated by the spatial coordinate system and the direct integration method [50]. In addition, the surface temperatures were given from the thermal images, and the sky temperature was considered to be equal to the ambient air temperature. The MRT is one of the parameters that affect thermal comfort of the human body, and the height of $1.5 \mathrm{~m}$ is a common height for outdoor thermal comfort evaluation. As a consequence, thermal radiation to a pedestrian can be evaluated by calculating the MRT distribution at this height.

$$
\begin{gathered}
\text { MRT }=\sqrt[4]{\frac{\sum_{i=1}^{n} \varepsilon_{i} F_{i} T_{S_{i}}{ }^{4}+F_{\text {sky }} T_{\text {sky }}{ }^{4}}{\varepsilon_{0}}} \\
\mathrm{MRT}=\sqrt[4]{\sum_{i=1}^{n} F_{i} T_{S_{i}}{ }^{4}+F_{\text {sky }} T_{\text {sky }}{ }^{4}}
\end{gathered}
$$



Figure 2. Radiation exchange between the human and surrounding surfaces based on 3D thermography in a pedestrian space.

\section{Case Study}

In order to analyze the thermal environment in pedestrian space under different environmental conditions, two pedestrian spaces around teaching buildings and dormitory buildings in Guangxi University were selected for field measurements to collect thermal images and aerial photography. 3D thermal images of these two pedestrian spaces were obtained by the method described. MRT distributions were also estimated and used to analyze the thermal effect.

\subsection{Thermal Environment in Pedestrian Space around the Teaching Buildings}

The pedestrian space analyzed is located in the teaching buildings district of Guangxi University. On the north is the Fourth Teaching Building with a height of $10 \mathrm{~m}$, and on the south is the Fifth Teaching Building whose height is about $12 \mathrm{~m}$. The building interval is $10 \mathrm{~m}$ and the ground is concrete-paved with little greening.

The 3D model and 178 pieces of 2D thermal images captured by the infrared camera were used to generate the 3D thermal image around the pedestrian space, as shown in Figure 3. MRTs at four locations (A, B, C, D) in this space were estimated by Equation (2), as shown in Figure 4. The four locations were at the middle of the pedestrian space, and their altitudes were $1.5 \mathrm{~m}$ above the ground.

As can be seen from the 3D thermal images shown in Figure 3c, the surface temperature of the building façade on the north of the street was higher than that on the south, because the former was exposed to the sun. The highest temperature was about $44^{\circ} \mathrm{C}$, and the lowest temperature for the latter 
was $28^{\circ} \mathrm{C}$ or so. Moreover, the ground temperature in the pedestrian space had an obvious boundary, and the maximum temperature difference was nearly $10^{\circ} \mathrm{C}$.

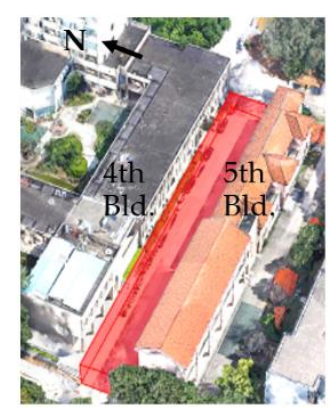

(a)

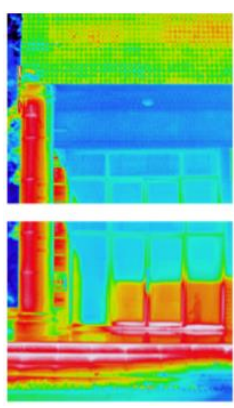

(b)

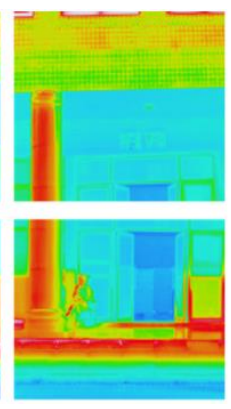

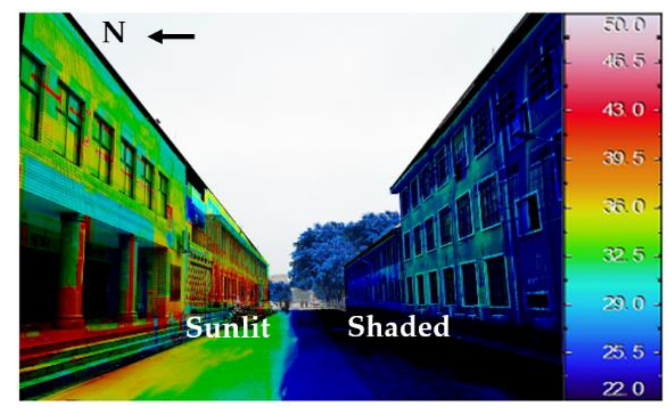

(c)

Figure 3. 3D models and thermal images around the teaching buildings. (a) 3D model; (b) thermal images taken at 14:00, 24 December 2018; (c) 3D thermography jointed from 178 pieces of 2D thermal images.

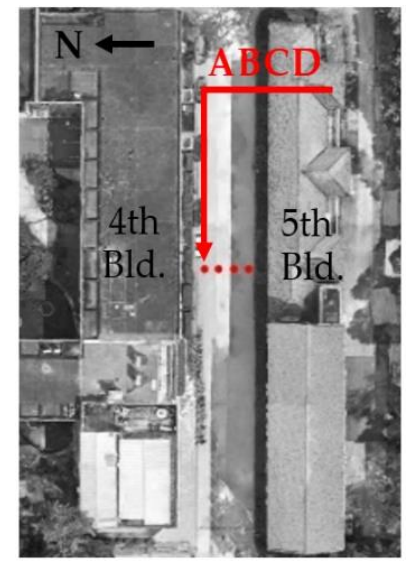

(a)



(b)

Figure 4. Locations and MRT values at analysis points A-D in the pedestrian space between the teaching buildings. (a) Locations of analysis points A-D; (b) MRT values at points A-D.

Figure 4 a shows the location of four analysis points (A, B, C, D) in the pedestrian space between the teaching buildings, and Figure $4 \mathrm{~b}$ gives the MRT value at these points. The highest value of MRT appeared at location A and the lowest MRT value was at location D. Their values were $25.8^{\circ} \mathrm{C}$ and $22.8^{\circ} \mathrm{C}$, respectively, and their MRT difference was $3^{\circ} \mathrm{C}$. In addition, location A was exposed to direct sunlight, and location B was located at the boundary of the sunlit and shaded ground. Locations $\mathrm{C}$ and $\mathrm{D}$ were in the shade, while location $\mathrm{D}$ was close to a little greening. From the analysis, it can be seen that the MRT in the sunlit location was about $3^{\circ} \mathrm{C}$ higher than that in the shade.

\subsection{Thermal Environment in Pedestrian Space around the Dormitory Buildings}

Another analyzed area is the pedestrian space in the dormitory district, as shown in Figure 5a. Both the north and south sides of the street are two 7-story dormitory buildings (21st and 22nd Building) with a height of $24 \mathrm{~m}$, and an overhead space on the first floor. The interval between these two buildings is $15 \mathrm{~m}$, and there is concrete pavement and some vegetation on the ground.

$3 \mathrm{D}$ thermal images shown in Figure $5 \mathrm{c}$ were prepared using the 3D model of the dormitory buildings and 168 pieces of $2 \mathrm{D}$ thermal images around the buildings. The MRT values at four analysis points (locations E, F, G, H) are indicated in Figure 6. 
As can be seen from Figure 5c, the northern building façade in the pedestrian space was irradiated by direct solar radiation, so it showed higher surface temperatures, with a maximum temperature of $52{ }^{\circ} \mathrm{C}$. In contrast, the building façade on the south of the pedestrian space was on the shaded side, and its surface temperatures were mostly below $30^{\circ} \mathrm{C}$.

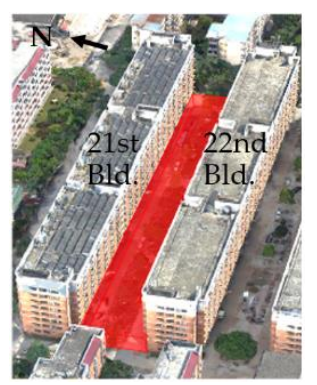

(a)

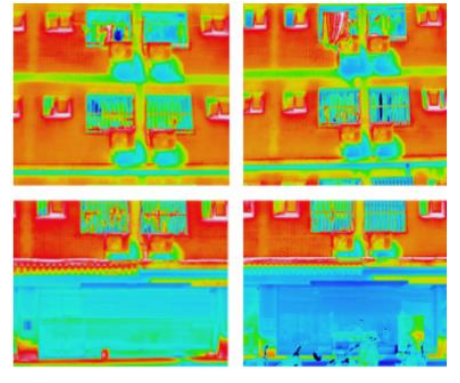

(b)



(c)

Figure 5. 3D models and thermal images around the dormitory buildings. (a) 3D model; (b) thermal images taken at 14:00, 20 September 2018; (c) 3D thermography jointed from 168 pieces of thermal images.

Thermal comfort in the pedestrian space between the two dormitory buildings was analyzed in terms of MRT at the four locations (E, F, G, H). As indicated in Figure 6, it is obvious that the MRT value decreased from location $\mathrm{E}\left(31.1^{\circ} \mathrm{C}\right)$ to location $\mathrm{H}\left(30.3^{\circ} \mathrm{C}\right)$, and the maximum MRT difference between them was $0.8{ }^{\circ} \mathrm{C}$. This occurred because the 21 st and 22 nd dormitory buildings are higher and the street aspect ratio $(\mathrm{H} / \mathrm{W})$ is large, thus blocking direct solar radiation from entering the space between the two buildings [51], so that the pedestrian space was in the shade for several hours during the daytime and its MRT values at all measurement points varied slightly. In other words, thermal comfort in the pedestrian spaces is related to its aspect ratio (H/W) [52].

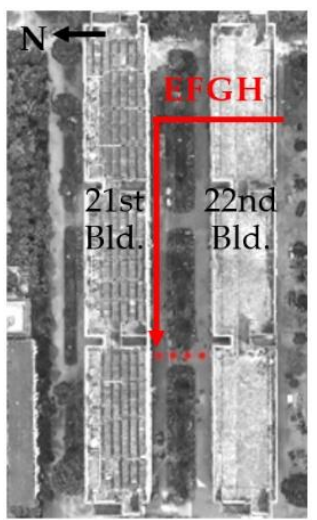

(a)

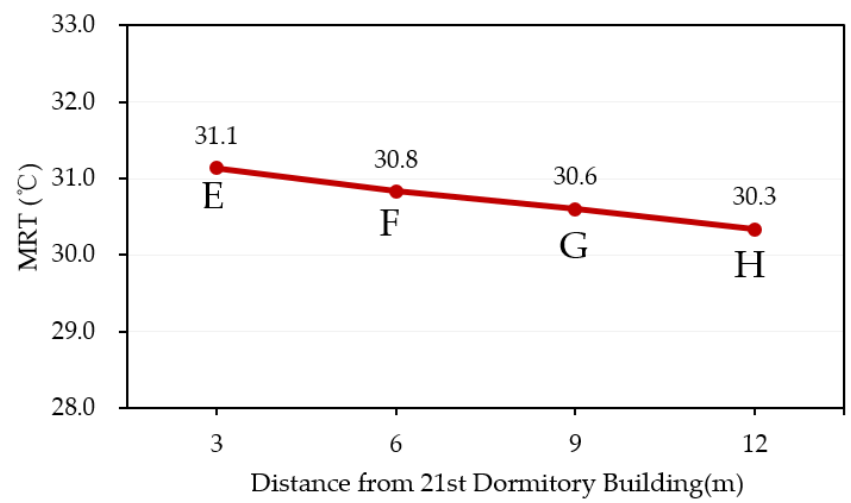

(b)

Figure 6. Locations and MRT values at analysis points E-H in the pedestrian space between the teaching buildings. (a) Locations of analysis points E-H; (b) MRT values at points E-H.

\subsection{Spatial Distribution of MRT around the Teaching Buildings}

Points at three different levels, $0.5,1$ and $1.5 \mathrm{~m}$, were selected to analyze the MRT distribution at different analysis points more intuitively. The distance between adjacent analysis points along the building façade was $8 \mathrm{~m}$ and the distance between adjacent analysis points vertical to the building façade was $2 \mathrm{~m}$. A total of 144 analysis points were chosen at the three different heights. The position and numbering of the analysis points are shown in Figure 7. The MRT values for the analysis points were estimated by Equation (2). 


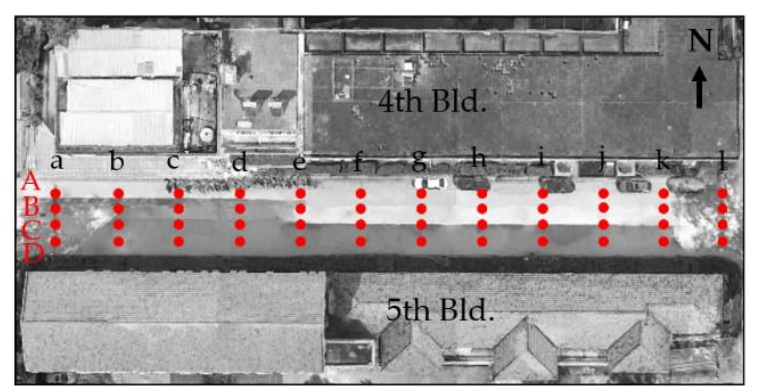

(a)

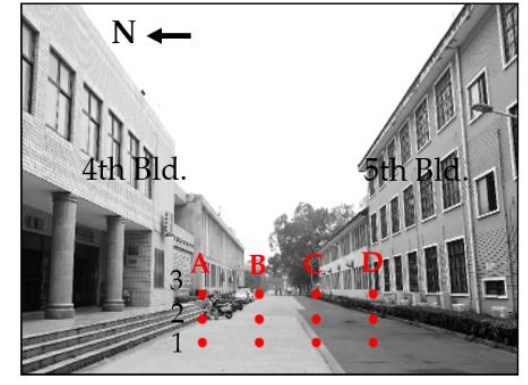

(b)

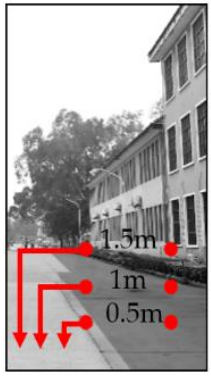

(c)

Figure 7. Locations of analysis points in the pedestrian space between the teaching buildings. (a) Measurement points in the analyzed pedestrian space; (b) measurement points along the height direction; (c) elevations of measurement points along the height direction.

A 3D thermal image was prepared using 2D thermal images captured on 30 September, as shown in Figure 8. MRT values at the 144 analysis points are also indicated with circles in Figure 8. In order to study MRT variation in the spatial distribution, the MRT values at 144 measurement points are plotted in Figure 9. From Figures 8 and 9, the following results are found:

- At the same height, the MRT values at the analysis points in any column (such as points A1, B2, C3 and D3) followed the same trend, first of all rising, then holding steady, before finally decreasing rapidly. This is because the start and end points were closer to the lower temperature façades in the pedestrian space, and their MRT values were lower. Meanwhile the MRT values at the analysis points in the same row (e.g., A1-a, B1-a, C1-a and D1-a) also followed the order of A > B > C > D. Because analysis points $A$ and $B$ were in the sunlit area, analysis point $C$ was at the junction of the sunlit and shaded areas, and analysis point $\mathrm{D}$ was in the shade, the ordering is $\mathrm{A}>\mathrm{B}>\mathrm{C}>\mathrm{D}$.

- The distance between the analysis points (A1, A2, A3) and the building was equal, while the MRT values for the same position along the length of the building façade decreased as the height increased, i.e., A3-a < A2-a < A1-a. This is because, for the same position, the closer the analysis point was to the ground, the higher its temperature, making the MRT value higher.

- The height of thermal comfort evaluation for pedestrian feet is $0.5 \mathrm{~m}$ when walking. At this height, the highest MRT value, $39.0^{\circ} \mathrm{C}$, appears in column A1 (analysis points $\mathrm{f}, \mathrm{g}, \mathrm{h}$ and $\mathrm{i}$ ). The lowest MRT value, $33.5^{\circ} \mathrm{C}$, appears in column D1 (analysis points a and 1), with a temperature difference of $5.5^{\circ} \mathrm{C}$.

- The average height of thermal comfort evaluation for children is $1.0 \mathrm{~m}$. In Figure $9 \mathrm{~b}$, it can be seen that the highest and lowest MRT values appear in column A2 (analysis points $\mathrm{g}$ and $\mathrm{h}$ ) and D2 (analysis points a and 1), with temperatures of $38.8^{\circ} \mathrm{C}$ and $32.9^{\circ} \mathrm{C}$, respectively, and a temperature difference of $5.9^{\circ} \mathrm{C}$.

- The average height of thermal comfort evaluation for adults is $1.5 \mathrm{~m}$. As seen in Figure 9c, it is obvious that the highest MRT value appears in the middle of column A3 (analysis points $\mathrm{f}$, $\mathrm{g}$, $\mathrm{h}$ and i), i.e., $38.6^{\circ} \mathrm{C}$. The lowest MRT value appears at the beginning and end of column D3 (analysis points a and 1), with a temperature of $32.7^{\circ} \mathrm{C}$ and a temperature difference of $5.9{ }^{\circ} \mathrm{C}$. 


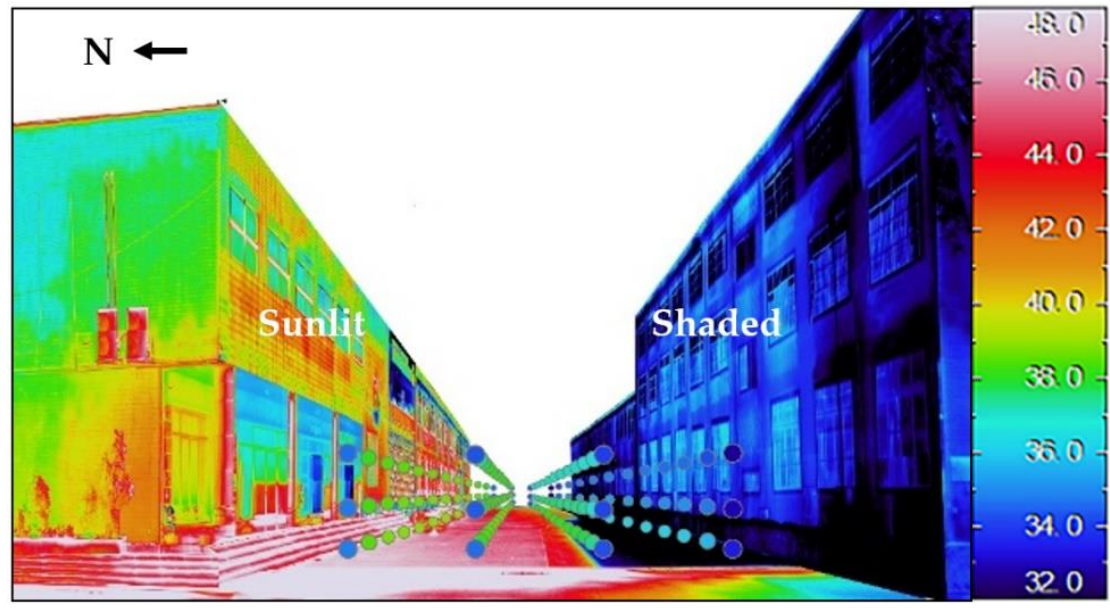

Figure 8. Spatial distribution of MRT values in the pedestrian space between the teaching buildings.

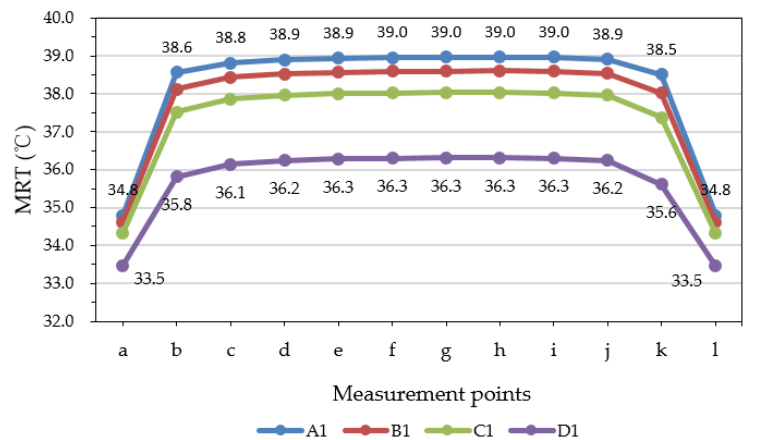

(a)

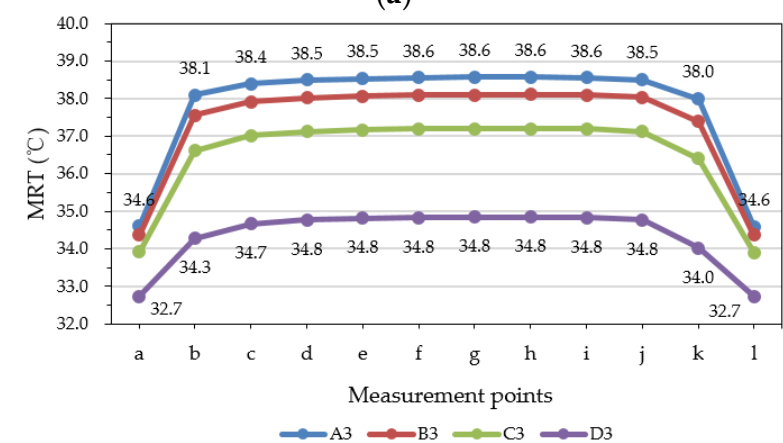

(c)

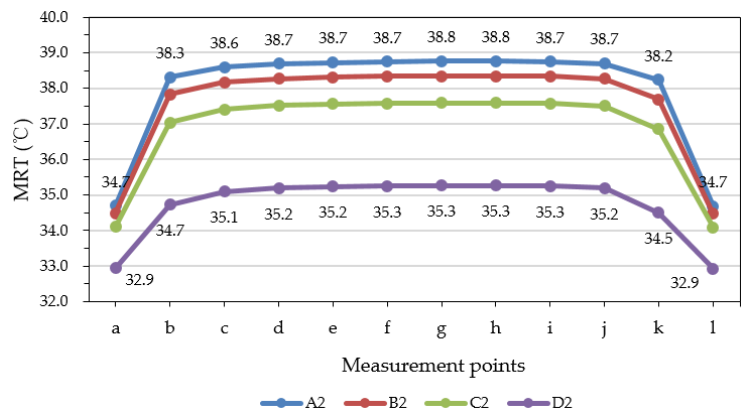

(b)

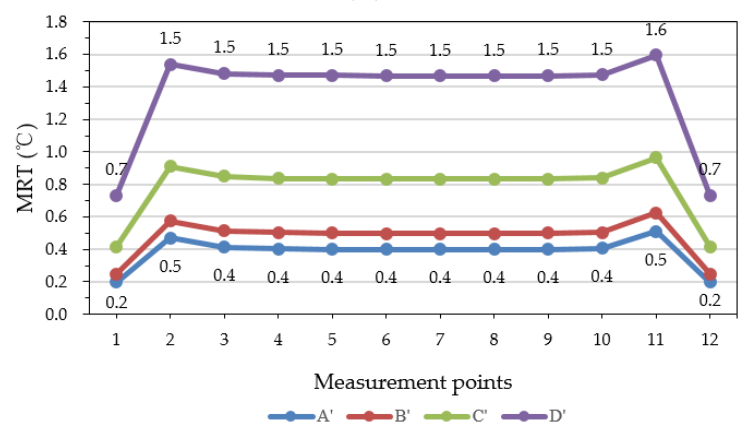

(d)

Figure 9. MRT variation in the pedestrian space between the teaching buildings. (a) MRT values at a height of $0.5 \mathrm{~m}$; (b) MRT values at $1 \mathrm{~m}$; (c) MRT values at $1.5 \mathrm{~m}$; (d) MRT differences between points at heights of 0.5 and $1.5 \mathrm{~m}$.

Taking the estimations for the 48 analysis points at the height of 0.5 and $1.5 \mathrm{~m}$, a different analysis was conducted to compare the MRT values at different heights and analysis points. As seen in Figure $9 \mathrm{~d}$, the trend for the MRT differences at $\mathrm{A}^{\prime}, \mathrm{B}^{\prime}, \mathrm{C}^{\prime}$ and $\mathrm{D}^{\prime}$ is consistent with variation for each column. In other words, the value initially rises, remains steady, then rapidly decreases. The MRT difference at $\mathrm{D}^{\prime}$ in the shaded area, is the highest for the analysis points in the same row, with a maximum value of 1.6 ${ }^{\circ} \mathrm{C}$. The MRT differences for $\mathrm{B}^{\prime}$ and $\mathrm{D}^{\prime}$ are lower. $\mathrm{A}^{\prime}$ is lowest, with a value of $0.2^{\circ} \mathrm{C}$. This is because the analysis points in column A were exposed to solar radiation for a longer time, so their MRT values did not vary so much in relation to their horizontal height. However, the analysis points in column D were in the shade and affected by surrounding vegetation. The closer to vegetation, the greater the influence of the lower temperature $[53,54]$ was observed. Thus, the MRT values at different altitudes varied greatly. 


\subsection{Validation of MRTs Estimated with Thermal Images}

In order to verify applicability and accuracy of the proposed method to estimate the MRT, a measurement comparison was conducted in an enclosed courtyard at the campus of Guangxi University. As shown in Figure 10a, there are three badminton courts in the courtyard, and trees are in the corners of the courtyard. Heights of the surrounding buildings are 10, 12, 18 and $29 \mathrm{~m}$. In the measurement, a black globe thermometer was used to measure the MRT, and the MRT is estimated by Equation (3), where $T_{a}$ and $T_{g}$ are the air temperature and the black globe temperature, respectively, and $V$ is wind velocity. Thermal images in the courtyard were captured in the daytime on a sunny summer day; Figure $10 \mathrm{~b}$ is thermography taken at an afternoon hour. Globe temperatures were simultaneously measured using the globe thermometer at three measurement locations $(\mathrm{H}, \mathrm{I}$ and $\mathrm{J})$. As indicated in Figure 10a,c, there are three measurement points with different heights $(1,1.5$ and $2 \mathrm{~m})$ at each measurement location.

$$
\mathrm{MRT}=T_{g}+2.44 \sqrt{V}\left(T_{g}-T_{a}\right)
$$

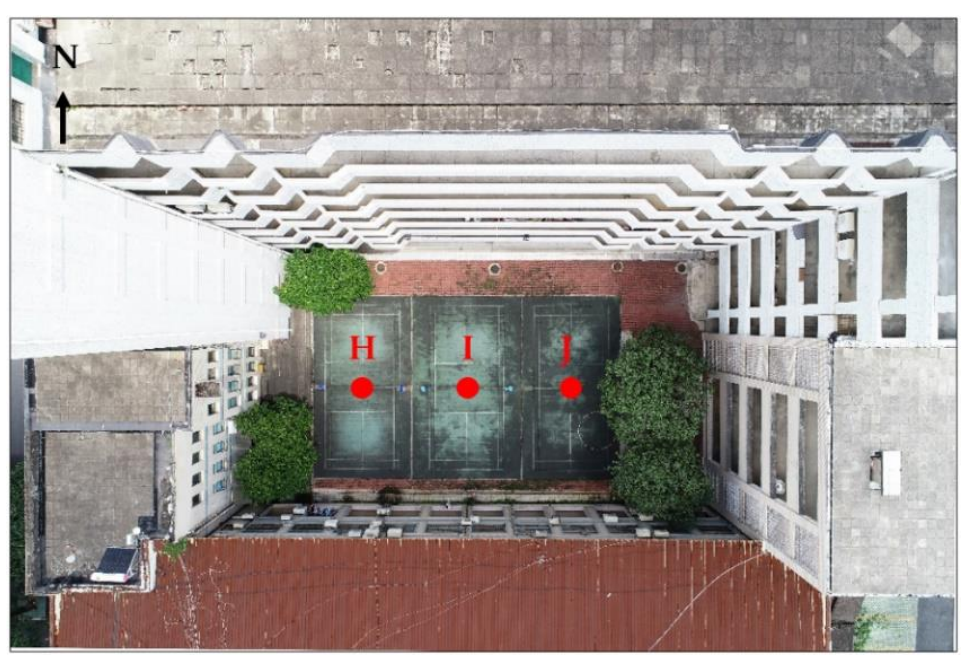

(a)



(b)

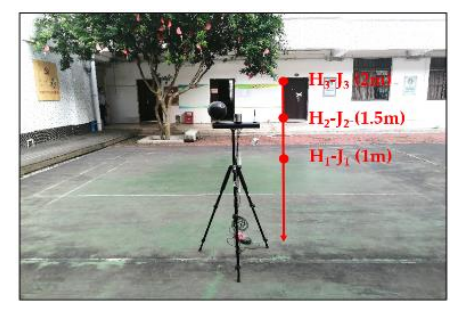

(c)

Figure 10. Locations of measurement points and thermal images in the enclosed courtyard. (a) Measurement points H, I, J; (b) thermal images of surrounding surfaces in the courtyard, taken in daytime on a sunny day; (c) globe thermometer (measurement instrument).

Figure 11 gives a comparison of MRTs estimated with the globe thermometer and thermal images. From Figure 11a-c, it can be seen that the MRT at three measurement points with different heights for each measurement location decreased with increasing measurement height, and there is a similar trend of MRT variation for these two approaches to estimate the MRT. For different measurement locations, a similar trend of MRT variation was also found for the two approaches, as shown in Figure 11d-f. In addition, there is good agreement with a difference of about $0.5^{\circ} \mathrm{C}$ in estimated MRT values from the two approaches. The MRT from thermal images (the proposed method) shows a slightly higher value than that from the globe thermometer. The reason for this is because the sky temperature was assumed to be the ambient air temperature in the estimation equation, i.e., Equation (2). 


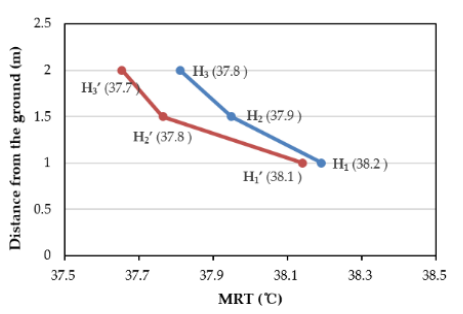

(a)

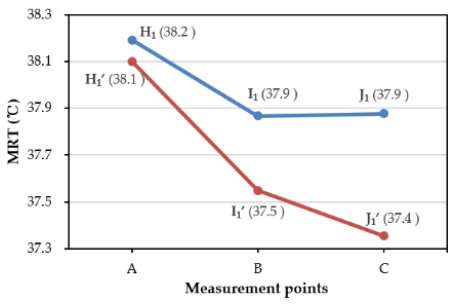

(d)



(b)

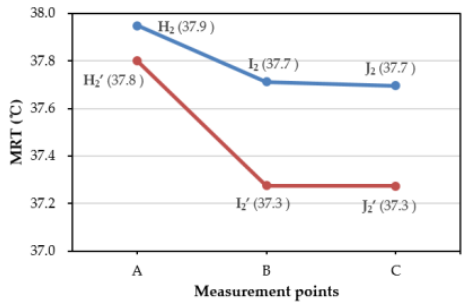

(e)

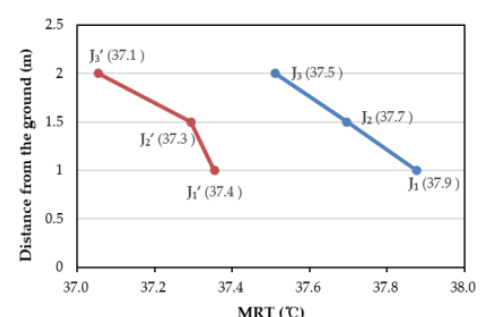

(c)

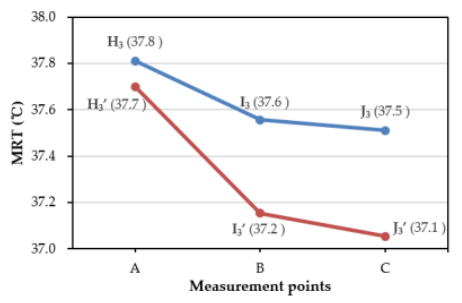

(f)

$\rightarrow$ From thermal images

From globe thermometer

Figure 11. Comparison of MRTs estimated from measured data of the globe thermometer and thermal images at the same measurement time. (a) MRT values for measurement points at heights of 1, 1.5 and $2 \mathrm{~m}$ at location $\mathrm{H}$; (b) MRT values for measurement points at heights of 1, 1.5 and $2 \mathrm{~m}$ at location I; (c) MRT values for measurement points at heights of 1, 1.5 and $2 \mathrm{~m}$ at location J; (d) MRT values at $1 \mathrm{~m}$ high at three locations H-J; (e) MRT values at $1.5 \mathrm{~m}$ high at three locations H-J; (f) MRT values at $2 \mathrm{~m}$ high at three locations $\mathrm{H}-\mathrm{J}$.

\section{Discussion}

Although the thermal environment in pedestrian space is primarily controlled by the amount of solar radiation, vegetation, paving materials etc., the methods for selecting appropriate evaluation indicators for studying the spatial distribution of thermal comfort remain largely unclear. Few previous studies have focused on the differences in spatial distribution, with most of the comparison generally focused on the spatiotemporal distribution [55]. However, the most important purpose to study thermal comfort in pedestrian spaces is to explore the factors that cause differences in spatial distribution and to propose suggestions for further mitigation. Therefore, this study proposed a method to acquire 3D thermal images, and discussed how to analyze the spatial distribution differences of MRT.

\subsection{D Thermal Image Visualization}

A 3D thermal image can be obtained by combining a UAV with an infrared camera. Its object is to detect the thermal radiation in the observed area. So this intuitive and simple method makes military survey, land detection, urban planning and other work more convenient [30,34]. This method also has the following limitations. Since aerial photography and thermal image collection are carried out simultaneously, this work requires more staff to cooperate. Secondly, more image data must be processed and the workload is larger, so it is not recommended for large study areas. Nevertheless, for thermal environment evaluation, 3D thermal images can support planners and designers working to conduct macroregional research, to evaluate mesoscale distribution and to analyze micro-observation [29]. Therefore, through the analysis for two different pedestrian spaces described in this study, it was found that the spatial morphology of shaded space has a great positive effect on thermal comfort in outdoor space. 


\subsection{Analysis of MRT in Pedestrian Space}

Since solar radiation is one of the greatest factors affecting outdoor thermal comfort, the MRT was selected as an evaluation index to analyze the thermally radiant environment in pedestrian space [19]. In the case study, the aspect ratio in the pedestrian space around the teaching buildings was small, the shaded area created by the building was also small, and so the MRT difference between the analysis points was sometimes as much as $3^{\circ} \mathrm{C}$. As the aspect ratio in the pedestrian space between the dormitory buildings was larger and there was a lot of vegetation, most of the analysis points were in the shade, so the MRT difference was smaller, being about $0.8^{\circ} \mathrm{C}$. In addition, it can be seen that thermal comfort in the pedestrian space is related to the aspect ratio and surrounding vegetation [35]. Thermal comfort can be improved since the MRT values decrease with increase of vegetation.

From the MRT spatial distribution shown in Figure 8, it can be seen that the MRT values for analysis points $\mathrm{A}, \mathrm{B}, \mathrm{C}$ and $\mathrm{D}$ at different altitudes had a declining trend, i.e., $\mathrm{A}>\mathrm{B}>\mathrm{C}>\mathrm{D}$. As analysis point $C$ was at the junction of direct sunlight and shade, analysis point $D$ was completely in the shade, and their MRT values had the largest decline. Meanwhile, the MRT values for three analysis points in the same series (e.g., A1, A2 and A3) decreased with height increase. Analysis point D (in the shade) underwent the largest decline, approximately $1.6^{\circ} \mathrm{C}$.

\subsection{Combination with Other Application Software}

There are few studies on spatial thermal environment evaluation and analysis based on UAV and thermal images. The combination of two technologies can make up for their shortcomings and improve the accuracy and applicability of 3D thermal images [32,33]. Although the study area is relatively small and there are more data to be processed, there are also high technical requirements for the operators in the image processing. Consequently, in order to simplify the data processing, future work will focus on the pedestrian route planning through extraction of MRT data in the pedestrian space based on software. Furthermore, it can combine map software to program a best walking route.

\section{Conclusions}

This paper has presented how to analyze and evaluate the thermal environment in pedestrian space using 3D thermal images from the data captured by a drone and infrared camera. The major findings follow.

Three-dimensional thermal images can effectively visualize surface temperature distribution at any angle in the study area. A thermal image is obtained by combining 3D models captured by the drone and 2D thermal images collected by the infrared camera. Meanwhile, MRT can be estimated from 3D thermal images at an analyzed point. Therefore, the outdoor thermal environment can be quantitatively analyzed and evaluated in terms of MRT.

Two pedestrian spaces around the teaching buildings and dormitory buildings in a university campus were selected as the case study objects to analyze the thermal environment in pedestrian spaces with different environmental conditions. According to measurement data and analysis results, it was found that the MRT difference in the pedestrian space with sunlit and shaded surfaces was more than $3{ }^{\circ} \mathrm{C}$, and the MRT values varied slightly in the pedestrian space with smaller aspect ratio and high vegetation around the dormitory buildings.

From the spatial MRT distribution, it can be seen that the MRT at different heights in the sunlit area is larger than that in the shaded area, with a maximum difference of $1.6^{\circ} \mathrm{C}$. Therefore, the most effective strategy to create a comfortable pedestrian space is to shade the space as much as possible.

Author Contributions: Conceptualization, J.H. and Y.L.; data curation, X.Z.; funding acquisition, J.H.; investigation, X.Z.; methodology, J.H.; software, Y.L.; writing—original draft preparation, X.Z.; writing一review and editing, J.H. All authors have read and agreed to the published version of the manuscript.

Funding: This research was funded by the National Natural Science Foundation of China (Grant No.51968003). 
Acknowledgments: The authors are grateful for their cooperation and help in field measurement and data processing: Nanxiong Huang, Yigan Li, Junmu Qiu and Peng Liu.

Conflicts of Interest: The authors declare no conflict of interest.

\section{References}

1. Jin, H.; Liu, S.Q.; Kang, J. Thermal comfort range and influence factor of urban pedestrian streets in severe cold regions. Energy Build. 2019, 198, 197-206. [CrossRef]

2. Eliasson, I.; Knez, I.; Westerberg, U.; Thorsson, S.; Lindberg, F. Climate and behaviour in a Nordic city. Landsc. Urban Plan. 2007, 82, 72-84. [CrossRef]

3. Xu, M.; Hong, B.; Jiang, R.; An, L.; Zhang, T. Outdoor thermal comfort of shaded spaces in an urban park in the cold region of China. Build. Environ. 2019, 155, 408-420. [CrossRef]

4. Shooshtarian, S.; Lam, C.K.C.; Kenawy, I. Outdoor thermal comfort assessment: A review on thermal comfort research in Australia. Build. Environ. 2020, 177, 106917. [CrossRef]

5. Kumar, P.; Sharma, A. Study on importance, procedure, and scope of outdoor thermal comfort-A review. Sustain. Cities Soc. 2020, 61, 102297. [CrossRef]

6. Ma, X.; Fukuda, H.; Zhou, D.; Gao, W.J.; Wang, M.Y. The study on outdoor pedestrian thermal comfort in blocks: A case study of the Dao He Old Block in hot-summer and cold-winter area of southern China. Sol. Energy 2019, 179, 210-225. [CrossRef]

7. Ma, X.; Fukuda, H.; Zhou, D.; Wang, M.Y. Study on outdoor thermal comfort of the commercial pedestrian block in hot-summer and cold-winter region of southern China-a case study of The Taizhou Old Block. Tour. Manag. 2019, 75, 186-205. [CrossRef]

8. Rakha, T.; Gorodetsky, A. Review of Unmanned Aerial System (UAS) applications in the built environment: Towards automated building inspection procedures using drones. Automat. Constr. 2018, 93, 252-264. [CrossRef]

9. Maes, W.H.; Huete, A.; Steppe, K. Optimizing the processing of UAV-based thermal imagery. Remote Sens. 2017, 9, 476. [CrossRef]

10. Golasi, I.; Salata, F.; De Lieto Vollaro, E.; Coppi, M. Thermal Perception in the Mediterranean Area: Comparing the Mediterranean Outdoor Comfort Index (MOCI) to Other Outdoor Thermal Comfort Indices. Energies 2016, 9, 550. [CrossRef]

11. Yin, S.; Lang, W.; Xiao, Y.Q. The synergistic effect of street canyons and neighbourhood layout design on pedestrian-level thermal comfort in hot-humid area of China. Sustain. Cities Soc. 2019, 49, 101571. [CrossRef]

12. Zhang, Y.F.; Du, X.H.; Shi, Y.R. Effects of street canyon design on pedestrian thermal comfort in the hot-humid area of China. Int. J. Biometeorol. 2017, 61, 1421-1432. [CrossRef]

13. Kang, G.; Kim, J.J.; Choi, W. Computational fluid dynamics simulation of tree effects on pedestrian wind comfort in an urban area. Sustain. Cities Soc. 2020, 56, 102086. [CrossRef]

14. Du, Y.X.; Mak, C.M.; Li, Y.T. A multi-stage optimization of pedestrian level wind environment and thermal comfort with lift-up design in ideal urban canyons. Sustain. Cities Soc. 2019, 46, 101424. [CrossRef]

15. Martinelli, L.; Matzarakis, A. Influence of height/width proportions on the thermal comfort of courtyard typology for Italian climate zones. Sustain. Cities Soc. 2017, 29, 97-106. [CrossRef]

16. Yang, Y.J.; Zhou, D.; Gao, W.J.; Zhang, Z.H.; Chen, W.; Peng, W.C.Y. Simulation on the impacts of the street tree pattern on built summer thermal comfort in cold region of China. Sustain. Cities Soc. 2018, 37, 563-580. [CrossRef]

17. Yang, Y.J.; Zhou, D.; Wang, Y.P.; Ma, D.; Chen, W.; Xu, D.; Zhu, Z.Z. Economical and outdoor thermal comfort analysis of greening in multistory residential areas in Xi'an. Sustain. Cities Soc. 2019, 51, 101730. [CrossRef]

18. Su, X.W.; Wang, Z.J.; Xu, Y.Y.; Liu, N.C. Thermal comfort under asymmetric cold radiant environment at different exposure distances. Build. Environ. 2020, 178, 106961. [CrossRef]

19. Guo, H.S.; Aviv, D.; Loyola, M.; Teitelbaum, E.; Houchois, N.; Meggers, F. On the understanding of the mean radiant temperature within both the indoor and outdoor environment, a critical review. Renew. Sustain. Energy Rev. 2020, 117, 109207. [CrossRef]

20. ISO 15265-2004; Ergonomics of Thermal Environments-Strategy of Evaluation of the Risk for the Prevention of Constraints or Discomfort under Thermal Working Conditions; International Organisation for Standardization: Geneva, Switzerland, 2004. 
21. D'Ambrosio Alfano, F.R.; Palella, B.I.; Riccio, G. On the Transition Thermal Discomfort to Heat Stress as a Function of the PMV Value. Ind. Healthy 2013, 51, 285-296. [CrossRef]

22. Middel, A.; Lukasczyk, J.; Maciejewski, R. Sky View Factors from Synthetic Fisheye Photos for Thermal Comfort Routing-A Case Study in Phoenix, Arizona. Urban Plan. 2017, 2, 19-31. [CrossRef]

23. Gál, C.V.; Kántor, N. Modeling mean radiant temperature in outdoor spaces, A comparative numerical simulation and validation study. Urban Clim. 2020, 32, 100571. [CrossRef]

24. Roth, M.; Lim, V.H. Evaluation of canopy-layer air and mean radiant temperature simulations by a microclimate model over a tropical residential neighbourhood. Build. Environ. 2017, 112, 177-189. [CrossRef]

25. Krayenhoff, E.; James, V. Daytime Thermal Anisotropy of Urban Neighbourhoods: Morphological Causation. Remote Sens. 2016, 8, 108. [CrossRef]

26. Nardi, I.; Lucchi, E.; Rubeis, T.D.; Ambrosini, D. Quantification of heat energy losses through the building envelope: A state-of-the-art analysis with critical and comprehensive review on infrared thermography. Build. Environ. 2018, 146, 190-205. [CrossRef]

27. Jarrar, Z.A.; Alshibli, K.A.; AI-Raoush, R.I.; Jung, J. 3D measurements of hydrate surface area during hydrate dissociation in porous media using dynamic 3D imaging. Fuel 2020, 265, 116978. [CrossRef]

28. Edelman, G.J.; Aalders, M.C. Photogrammetry using visible, infrared, hyperspectral and thermal imaging of crime scenes. Forensic Sci. Int. 2018, 292, 181-189. [CrossRef] [PubMed]

29. Andraši, P.; Radišić, T.; Muštra, M.; Ivošević, J. Night-time Detection of UAVs using Thermal Infrared Camera. Transp. Res. Proc. 2017, 28, 183-190. [CrossRef]

30. Zhang, X.L.; Zhang, F.; Qi, Y.X.; Deng, L.F.; Wang, X.L.; Yang, S.T. New research methods for vegetation information extraction based on visible light remote sensing images from an unmanned aerial vehicle (UAV). Int. J. Appl. Earth Obs. 2019, 78, 215-226. [CrossRef]

31. Harvey, M.C.; Rowland, J.V.; Luketina, K.M. Drone with thermal infrared camera provides high resolution georeferenced imagery of the Waikite geothermal area, New Zealand. J. Volcanol. Geotherm. Res. 2016, 325, 61-69. [CrossRef]

32. Caldwell, S.H.; Kelleher, C.; Baker, E.A.; Lautz, L.K. Relative information from thermal infrared imagery via unoccupied aerial vehicle informs simulations and spatially-distributed assessments of stream temperature. Sci. Total Environ. 2019, 661, 364-374. [CrossRef] [PubMed]

33. Laguela, S.; Diaz-Vilarino, L.; Roca, D.; Lorenzo, H. Aerial thermography from low cost UAV for the generation of thermographic digital terrain models. Opto-Electron. Rev. 2018, 23, 76-82. [CrossRef]

34. Sudhakar, S.; Vijayakumar, V.; Sathiya Kumar, C.; Priya, V.; LogeshRavi, V.; Subramaniyaswamy, V. Unmanned Aerial Vehicle (UAV) based Forest Fire Detection and monitoring for reducing false alarms in forest-fires. Comput. Commun. 2020, 149, 1-16. [CrossRef]

35. Zhang, M.N.; Zhou, J.F.; Sudduth, K.A.; Kitchen, N.R. Estimation of maize yield and effects of variable-rate nitrogen application using UAV-based RGB imagery. Biosyst. Eng. 2020, 189, 24-35. [CrossRef]

36. Liu, C.; Cao, Y.J.; Yang, C.; Zhou, Y.; Ai, M.C. Pattern identification and analysis for the traditional village using low altitude UAV-borne remote sensing: Multifeatured geospatial data to support rural landscape investigation, documentation and management. J. Cult. Herit. 2018. [CrossRef]

37. Langhammer, J.; Bohumír, J.; Jan, K.; Robert, M. 3-D reconstruction of an abandoned montane reservoir using UAV photogrammetry, aerial LiDAR and field survey. Appl. Geogr. 2018, 98, 9-21. [CrossRef]

38. Da, L.; Carol, C.M.; Vineet, R.K. Robust non-intrusive interpretation of occupant thermal comfort in built environments with low-cost networked thermal cameras. Appl. Energy 2019, 251, 113336. [CrossRef]

39. Jiang, W.G.; Zhou, Y.; Ding, L.Y.; Zhou, C.; Ning, X.D. UAV-based 3D reconstruction for hoist site mapping and layout planning in petrochemical construction. Automat. Constr. 2019, 113, 103137. [CrossRef]

40. Hastaoğlu, K.Ö.; Gül, Y.; Poyraz, F.; Kara, B.C. Monitoring 3D areal displacements by a new methodology and software using UAV photogrammetry. Int. J. Appl. Earth Obs. 2019, 83, 101916. [CrossRef]

41. Colomina, I.; Molina, P. Unmanned aerial systems for photogrammetry and remote sensing: A review. ISPRS J. Photogramm. 2014, 92, 79-97. [CrossRef]

42. Previtali, M.; Barazzetti, L.; Redaelli, V.; Scaioni, M.; Rosina, E. Rigorous procedure for mapping thermal infrared images on three-dimensional models of building façades. J. Appl. Remote Sens. 2013, 7, 073503. [CrossRef]

43. Charlie Lam, C.K.; Hang, J. Solar Radiation Intensity and Outdoor Thermal Comfort in Royal Botanic Garden Melbourne during Heatwave Conditions. Procedia Eng. 2017, 205, 3456-3462. [CrossRef] 
44. Lai, P.Y.; Koh, J.H.; Koh, W.S.; Liu, H.Z. Effectively modeling surface temperature and evaluating mean radiant temperature in tropical outdoor industrial environments. Build. Environ. 2020, 169, 106277. [CrossRef]

45. Chen, Y.C.; Lin, T.P.; Matzarakis, A. Comparison of mean radiant temperature from field experiment and modelling: A case study in Freiburg, Germany. Theor. Appl. Climatol. 2014, 118, 535-551. [CrossRef]

46. Lee, D.S.; Kim, E.J.; Cho, Y.H.; Kang, J.W.; Jo, J.H. A field study on application of infrared thermography for estimating mean radiant temperatures in large stadiums. Energy AMP Build. 2019, 202, 109360. [CrossRef]

47. Chen, L.; Yu, B.L.; Yang, F.; Mayer, H. Intra-urban differences of mean radiant temperature in different urban settings in Shanghai and implications for heat stress under heat waves: A GIS-based approach. Energy Build. 2016, 130, 829-842. [CrossRef]

48. Wang, L.J.; Di, Y.H. Discussion on the application of mean radiant temperature. Heat. Ventil. Air Condition. 2015, 1, 87-90.

49. Sofia, T.; Fredrik, L.B.; Ingegärd, F.; Björn, H. Different methods for estimating the mean radiant temperature in an outdoor urban setting. Int. J. Climatol. 2007, 27, 1983-1993. [CrossRef]

50. Barry, M.; Ying, J.; Durka, M.J.; Clifford, C.E.; Reddy, B.V.K.; Chyu, M.K. Numerical solution of radiation view factors within a thermoelectric device. Energy 2016, 102, 427-435. [CrossRef]

51. Lee, H.; Holst, J.; Mayer, H. Modification of human-biometeorologically significant radiant flux densities by shading as local method to mitigate heat stress in summer within urban street canyons. Adv. Meteorol. 2013, 2013, 312572. [CrossRef]

52. Thorsson, S.; Honjo, T.; Lindberg, F.; Eliasson, I.; Lim, E.M. Thermal Comfort and outdoor activity in Japanese urban public places. Environ. Behav. 2007, 39, 660-684. [CrossRef]

53. Hassan Abdallah, A.S.; Hussein, S.W.; Nayel, M. The Impact of outdoor shading strategies on Student thermal comfort in Open Spaces Between Education Building. Sustain. Cities Soc. 2020, 2020, 102124. [CrossRef]

54. Coccolo, S.; Pearlmutter, D.; Kaempf, J.; Scartezzini, J.L. Thermal Comfort Maps to estimate the impact of urban greening on the outdoor human comfort. Urban For. Urban Green. 2018, 35, 91-105. [CrossRef]

55. Niu, L.; Tang, R.L.; Jiang, Y.Z.; Zhou, X. Spatiotemporal Patterns and Drivers of the Surface Urban Heat Island in 36 Major Cities in China: A Comparison of Two Different Methods for Delineating Rural Areas. Sustainability 2020, 12, 478. [CrossRef]

(C) 2020 by the authors. Licensee MDPI, Basel, Switzerland. This article is an open access article distributed under the terms and conditions of the Creative Commons Attribution (CC BY) license (http://creativecommons.org/licenses/by/4.0/). 